\title{
A Comparison Study on the Vertical Integration and Horizontal Specialization of Chinese ICT Companies
}

\author{
Yunju Chen \\ Faculty of Economics, Shiga University, \\ 1-1-1, Banba, Hikone City, Shiga Pref.,522-8522, Japan \\ Yousin Park \\ Dept. of Business Administration, Prefectural University of Hiroshima, \\ 1-1-71 Ujina-Higashi, Minami-ku, Hiroshima City, Hiroshima Pref., 734-8558, Japan \\ Iori Nakaoka \\ Dept. of Business Administration, National Institute of Technology, Ube College, \\ 2-14-1 Tokiwadai, Ube City, Yamaguchi Pref., 755-8555, Japan \\ E-mail: yun-chen@biwako.shiga-u.ac.jp,ecventure@pu-hiroshima.ac.jp,nakaoka@ube-k.ac.jp
}

\begin{abstract}
It is said that the decision of vertical integration or horizontal specialization (the boundary of the firm) affects a firm's profit and competitive advantage, especially in the ICT industry. This paper focused on top market share Chinese ICT companies in global smartphone industry, Xiaomi and Huawei, to examine how they design their boundary of operation systems in R\&D. Patent data analysis is used to investigate Xiaomi's and Huawei's technology strategies and technical networks, also to compare their systems with each other. According to the results of analysis, we suppose that Xiaomi has rough $R \& D$ organization structures and hence has low level of integration, which close to horizontal specialization. On the other hand, Huawei has high weight on internal R\&D, and explores technologies related to core technologies. Its R\&D structures are more highly integrated than Xiaomi.
\end{abstract}

Keywords: patent analysis, social network analysis, Chinese ICT companies, the boundary of the firm, vertical integration, horizontal specialization

\section{Introduction}

The global smartphone market has been changed dynamically during these years. After the year of 2012, the presence of Chinese ICT companies in the global smartphone market is getting higher and higher and they almost occupy the global top five positions besides Samsung and Apple.

Although the open source of Android lowers the entry barrier and benefit many Chinese ICT companies to extend their shares in the global market, they adapt various strategies, not simply the cost leadership strategy.
For example, Xiaomi is an internet startup with short company history, and its rapid growth tells a story that it may grow up by outsourcing. On the other hand, Huawei has been the giant smartphone firm with long history, and it is also one of the innovative Chinese firms that have top class filings of patents.

However, how Chinese ICT companies adopt different strategies, even the operation systems? It seems that Chinese ICT companies, like Xiaomi and Huawei, develop their operation systems by either make or buy. Actually, the decision of make or buy, in other words, vertical integration or horizontal specialization 
affects a firm's profit and competitive advantage. The debate between vertical integration vs. horizontal specialization appears to be reinvigorated, especially in the ICT industry which added value is difficult to create due to the commoditization of digital products.

In this paper, we focus on top market share Chinese ICT companies in global smartphone industry, Xiaomi and Huawei, to examine how they design their operation systems in R\&D and gain competitive advantages, also to compare their systems with each other. The patent information of these two companies is used to visualize their technical orientations, R\&D networks and operation systems in R\&D by text mining.

\section{Research Background}

\subsection{Open innovation and patent analysis}

In order to carry out various activities, companies inevitably cooperate with others to use external resources. At the same time, companies face the issue of what to outsource and how to manage their own systems while cooperating with other companies. The decision making of what and how to outsource from others refers to the issue of boundary of the firm.

To make or buy in the vertical flow of production is the typical issue of the boundary of the firm, however, not only in production, but also in R\&D. Theoretically, much attention has been drawing to the use of external resource in $R \& D$ to drive innovation, which is defined as open innovation. Open innovation is the use of purposive inflows and outflows of knowledge to accelerate internal innovation, and expand the markets for external use of innovation, respectively. This paradigm assumes that companies can and should use external ideas as well as internal ideas, and internal and external paths to market, as they look to advance their technology [1]. Horizontal specialization-oriented companies tend to outsource and cooperate with other companies, hence benefit from open innovation in R\&D.

The boundary of the firm in R\&D also concerns the national innovation system. The national innovation system is the network of institutions in the public and private sectors whose activities and interactions initiate, import, modify and diffuse new technologies [2].

To examine the boundary of firm in $R \& D$, patent analysis can be an effective visualization tool. The patent is one of the indicators to measure the capacity for technological development. The previous researches concentrate on visualizing and analyzing patents, or proposing efficient text-mining approaches for creating patent maps. However, there are few researches that use text-mining analysis of patents in the field of management to examine the $R \& D$ management strategies of firms. In this paper we use the patent analysis to reveal the characteristics of Chinese ICT companies' R\&D management and discuss the meaning in the R\&D strategy.

\subsection{The overview of Chinese ICT companies}

The global market share of smartphone surveyed by analyst firm IDC shows a major shakeup in the Chinese smartphone market from 2013. Fig. 1 shows that Huawei, Xiaomi and Lenovo, the Chinese ICT companies occupied the 3rd-5th share in the global market.

Xiaomi (Xiaomi Technology Co., Ltd) founded in 2010 by a well-known angel investor Lei Jun, and achieved impressive growth soon after its establishment. Xiaomi is a mobile internet company and focuses its businesses on smartphones (Xiaomi Phones), including the OS of MIUI, MiTalk, the e-commerce platform of Xiaomi.com etc. On the other hand, Huawei (Huawei Technologies Co. Ltd.) was founded in 1987, and started its business by producing private branch exchange switches. Now the company has become one of the top telecommunications equipment suppliers and has active R\&D activities since its existence. Its businesses comprise mobile and fixed broadband networks, smartphones, tablet computers etc. Fig. 2 shows ROE and profit margin of Xiaomi and Huawei. Xiaomi explosively expanded ROE in 2013 and 2014, but has low profit margin rate instead. On the other hand, Huawei maintains high ROE, and sustain high profit margin rate after 2009.

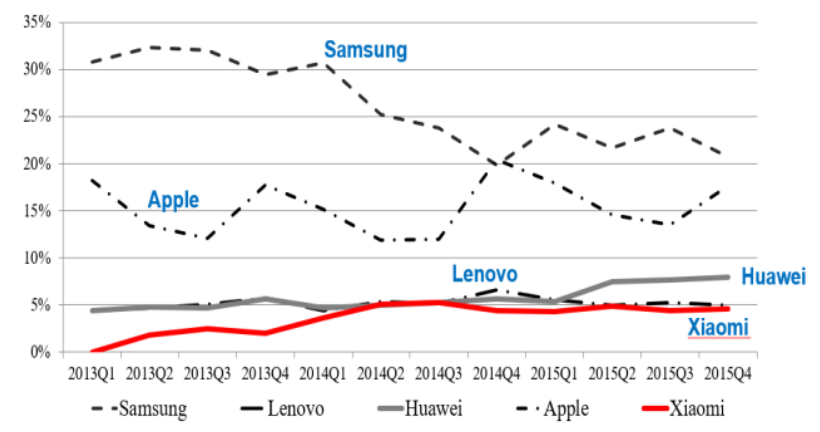

Fig.1. Global market share by vendors 


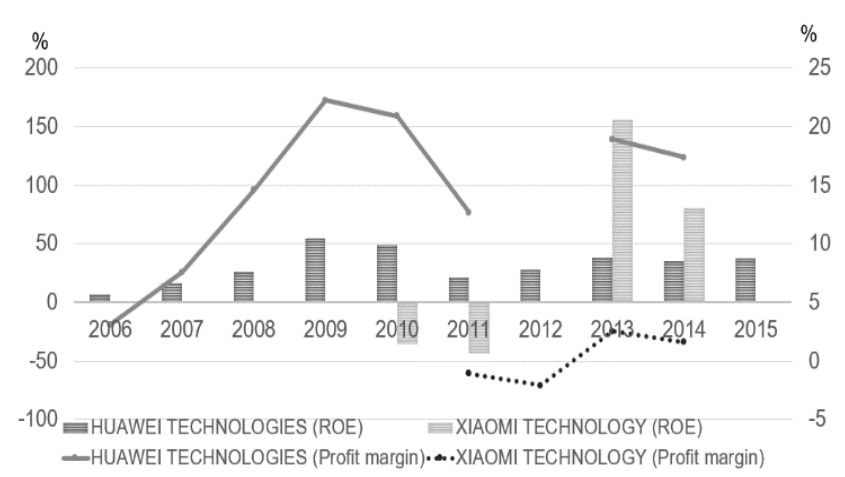

Fig.2. ROE of Xiaomi and Huawei

\section{Methodology and data}

In the following sections, the R\&D strategies/ operation systems of Chinese ITC companies are analyzed. In order to examine target companies' R\&D strategies and the change of core personnel in their $R \& D$ projects, we visualize their patent information by 3 types of approaches: the number of patent publications, correspondence analysis (categories of IPCs, correspondence analysis, and social network analysis (R\&D networks and core rigidity).

About the data, we use the IPC (International Patent Classification) code for analyzing the smartphone industry. IPC, established by the Strasbourg Agreement 1971, provides for a hierarchical system of language independent symbols for the classification of patents and utility models according to the different areas of technology to which they pertain.

Table 1 is the most frequently used IPC in smartphone industry. Based on these IPC related to smartphone, patents related to smartphone published by each company are extracted and collected from the patent information. In addition, the data was collected from 2010 to 2015 .

Table1 IPC classes of smartphone

\begin{tabular}{|c|c|}
\hline IPC & Description \\
\hline H01, H02 & $\begin{array}{l}\text { Electricity: Battery or Capacitor Charging or } \\
\text { Discharging }\end{array}$ \\
\hline H03, H04 & Coded Data Generation or Conversion \\
\hline G02 & Liquid Crystal Cells, Elements and Systems \\
\hline H02, F21 & Electricity: Electrical Systems and Devices \\
\hline H04,G01, G06, G08 & Multiplex Communications \\
\hline H03, H04 & Pulse or Digital Communications \\
\hline H04 & Telephonic Communications \\
\hline G02, H04 & Optical Communications \\
\hline H04 & Telecommunications \\
\hline G06, G10 & $\begin{array}{l}\text { Data Processing: Speech Signal Processing, } \\
\text { Linguistics, Language Translation, and } \\
\text { Audio Compression/Decompression }\end{array}$ \\
\hline G06 & Data Processing: Artificial Intelligence \\
\hline G06 & $\begin{array}{l}\text { Data Processing: Database and File } \\
\text { Management or Data Structures }\end{array}$ \\
\hline G06 & $\begin{array}{l}\text { Data Processing: Presentation Processing of } \\
\text { Document, Operator Interface Processing, } \\
\text { and Screen Saver Display Processing }\end{array}$ \\
\hline
\end{tabular}

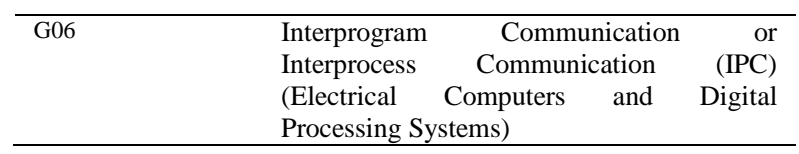

\section{Analysis}

\subsection{An approach based on the number of patent publications}

The numbers of patent publications related to smartphone of Xiaomi and Huawei are shown in Fig. 3. Each company obtains related patents to a certain extent and the number of patents of all of them kept on increasing during the years except for 2016.

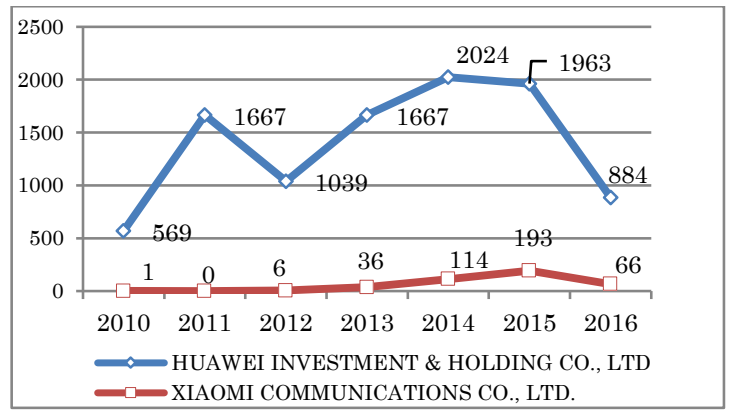

Fig.3. The number of patents of Huawei and Xiaomi

\subsection{An approach by correspondence analysis}

We use the correspondence analysis to disclose the technical trends and characteristics based on IPC codes associated with smartphone.

In the analysis, the reference data is the number of their patent document in each year. These figures are made based on dates of patent publication. Fig. 4 is the result of correspondence analysis of both companies. Although Xiaomi has few patents, the technologies it developed have low similarity with each other. Contrast to Xiaomi, there is technological continuity from 2011 to 2015 in Huawei, especially in the IPC code of H04.
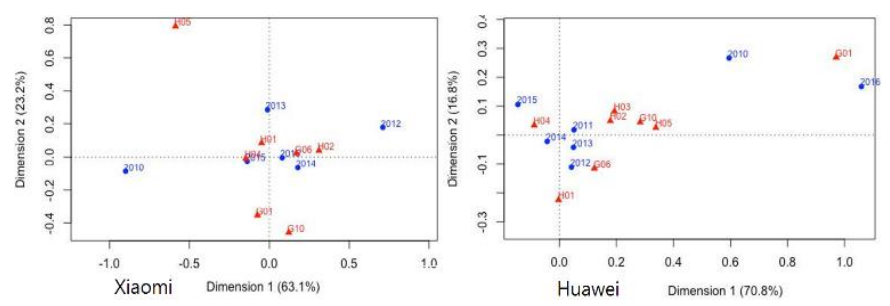

Fig.4. Results of correspondence analysis

\subsection{An approach by the social network analysis}

\subsection{1. $R \& D$ network}

Fig. 5 is the patent of core applicant network of Xiaomi, and Fig. 6 is Huawei's case. 
In Xiaomi's case, several islands that connected only to related patents are observed. It seems there is little relationship between technologies that Xiaomi developed every year. Co-research inside Xiaomi seems started at 2010, and organizational collaboration can be seen at 2015. On the other hand, the technology network of Huawei concentrated on several core patents and technologies are expanded based on these core patents. Core applicants constantly exist during the period, and collaboration network of core applicants form from 2011.

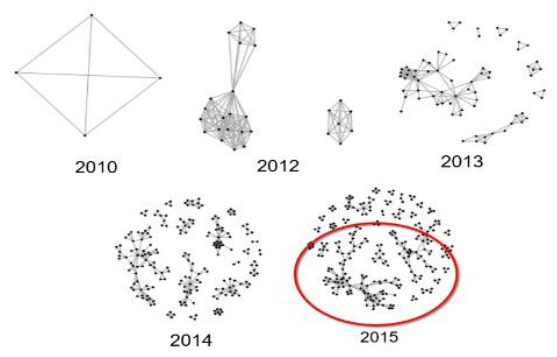

Fig.5. R\&D Networks of Xiaomi

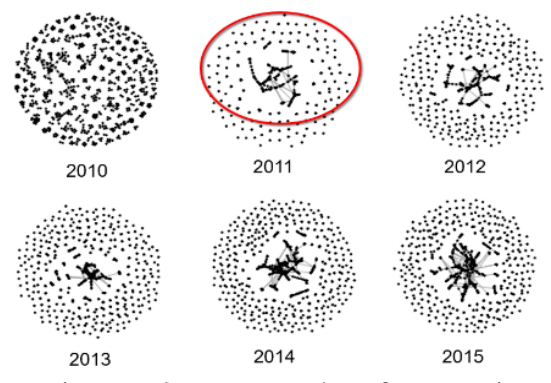

Fig.6. R\&D Networks of Huawei

\subsubsection{The evaluation of core rigidity in $R \& D$}

We define that patent applicants are key persons attaining high scores calculated by centrality of social network analysis. Freeman proposed three distinct conceptions of the most important index of centrality: degree, betweenness and closeness [3].

Core rigidity is defined in this paper as the equation that shows the degree of reallocation of personnel engaged in $R \& D$ projects (Core Rigidity $=$ Conditional Probability ((upper rank $\mathrm{j} \%$ of person at $\mathrm{i}+1$ year)/ (upper rank $\mathrm{j} \%$ of person at $\mathrm{i}$ year))). When such probability scores are high, core rigidity exist [4]. Results obtained by calculation are visualized in the form of heat-maps. Where the color is dark red in heat-map, it indicates an un-executed reallocation of core members; otherwise, the color is light red, which means radical changes of core members in that year.
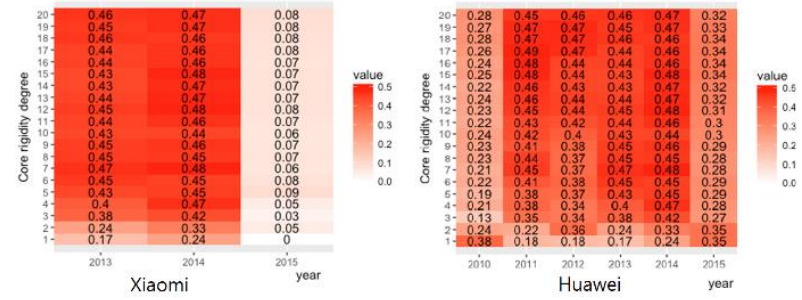

Fig.7. The core rigidity of Xiaomi and Huawei

The core rigidity of human resource and the change of R\&D area the personnel involved in Xiaomi and Huawei are shown in Fig. 7. Core personnel changed dynamically in recent years in Xiaomi, while Huawei's personnel retained for several years, in about a span of every 3 years.

\section{Conclusions}

This paper focused on Xiaomi and Huawei, the two major Chinese ICT companies to examine how they design their boundary of operation systems in R\&D. Patent analysis were used to investigate Xiaomi's and Huawei's technology strategies and technical networks. The results of analysis are summarized in Table 2 below.

Table 2 The summary of the analysis results

\begin{tabular}{lcc}
\hline Analysis & Xiaomi & Huawei \\
\hline $\begin{array}{l}\text { The number of patent } \\
\text { publications }\end{array}$ & grew fast & Increased Constantly \\
$\begin{array}{l}\text { Constitution of R\&D } \\
\text { network }\end{array}$ & Recently & From 2011 \\
\hline Core rigidities & High(recently) & Low(3-year-cycle) \\
\hline Changes of R\&D area & $\begin{array}{l}\text { Technological } \\
\text { discontinuity }\end{array}$ & $\begin{array}{c}\text { Technological } \\
\text { continuity }\end{array}$ \\
\hline
\end{tabular}

Based on the results of analysis, we supposed that Xiaomi probably acquires external related patents rather than develops its own technologies. Xiaomi has rough R\&D organization structures and hence has low level of integration, which close to horizontal specialization. In fact, Xiaomi has few manufacturing facilities of its own.

On the other hand, Huawei has high weight on internal $\mathrm{R} \& \mathrm{D}$, and explores technologies related to core technologies. Its R\&D structures are more highly integrated than Xiaomi. Huawei is increasing its emphasis on R\&D to become more innovative in a highly competitive and rapidly consolidating industry. Being able to continuously and successfully innovate through vertical integration, Huawei struggles for creating competitive advantages.

\section{References}

1. H. Chesbrough (2006) Open Innovation: Researching a New Paradigm, Oxford University Press 
2. Christopher Freeman (1987) Technology and Economic Performance: Lessons from Japan, Pinter, London

3. L. C. Freeman (1978) Centrality in Social Networks Conceptual Clarification, Social Networks, vol.1, pp.215239

4. Leonard-Barton, D. (1992). Core Capabilities and Core rigidities: A Paradox in Managing New Product Development. Strategic Management Journal, vol. 13: 111-125. 